\title{
Implementation of MIMO and AMC Techniques in WiMAX Network based VANET System
}

\author{
Prabhakar D. Dorge \\ Research Scholar, G. H. Raisoni College of Engineering, Nagpur, India \\ E-mail: prabhakar_dorge2007@rediffmail.com \\ Dr. Sanjay S. Dorle \\ G. H. Raisoni College of Engineering, Nagpur, India \\ E-mail: s_dorle@yahoo.co.uk \\ Megha B. Chakole \\ Yeshwantrao Chavan College of Engineering, Nagpur, India \\ E-mail: mdorle@gmail.com
}

\begin{abstract}
Vehicular Ad-hoc Networks (VANETs) are expected to implement wireless technologies such as Dedicated Short Range Communications (DSRC) which is a category of Wi-Fi. Other candidates of long distance wireless technologies are cellular, satellite, and WiMAX. VANETs can be viewed as component of the Intelligent Transportation Systems (ITS). This paper presents the implementation of Multiple Inputs Multiple Outputs (MIMO) and Adaptive Modulation and Coding (AMC) techniques in WiMAX based Vehicular Ad-hoc Network. This designed system provides multiple radio channels in between transmitter and receiver for transmission and reception of the data by using the concept of MIMO technology. Also AMC provides the selection of different modulation techniques depending on the signal to noise ratio of the channel. These two techniques provide the significant change in the throughput, delay, jitter, and packet delivery ratio and packet loss ratio than existing vehicular ad-hoc network. WiMAX based VANET provides high speed, low cost per bit and large coverage area.
\end{abstract}

Index Terms-WiMAX, Multiple Inputs Multiple Outputs, Adaptive Modulation and Coding, Vehicular Ad-hoc Network, Routing Protocols.

\section{INTRODUCTION}

These days, a vehicle can communicate with another vehicle and infrastructure by the development of hardware and software. These communications are able to provide an entertainment services and safety for passengers. Typically VANET is a combination of vehicle-to-infrastructure (V2I) communication and vehicle-to-vehicle (V2V) communication. To deal with the V2I communication the Road Side Units (RSUs) must be installed. With this vehicle can access the data from RSUs or can access the internet through these RSUs.

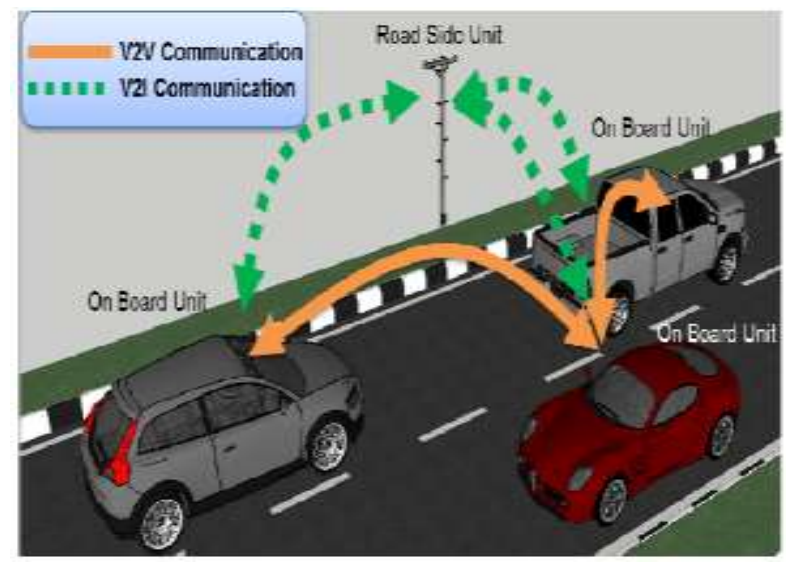

Fig.1. Typical Components of VANET

In figure 1 we can see that orange line indicates the communication between two vehicles without using Road Side Unit. The green lines indicate the communication between Road Side Units and different vehicles. On Board Unit (OBU) is one of VANET components. It is a communications module that provides a communication network for inter-vehicle and between vehicle and infrastructure. RSU is a communication device. Typically, RSU is installed on the road side. RSU sends a non-safety message mostly which is driverfriendly information such as traffic information, authentication messages, multimedia messages, and etc. The vehicle or RSU can send the safety messages to other vehicles. The safety messages include an emergency message such as emergency vehicle nearby approach warning, pre-crash and post-crash warning. This type of messages requires the short time delay unlike the nonsafety message because it is a type of emergency services. When the vehicle receives safety messages from other vehicle or RSU, it should respond to the message sender and other users quickly [1]. This types of VANET system provide the services like emergency data transfer, security warnings, internet facility, etc. For example if 
person is travelling from hilly region by his vehicle and if the road condition is not good or any disaster thing is happened, then this VANET system will provide security messages to that person to change the path.

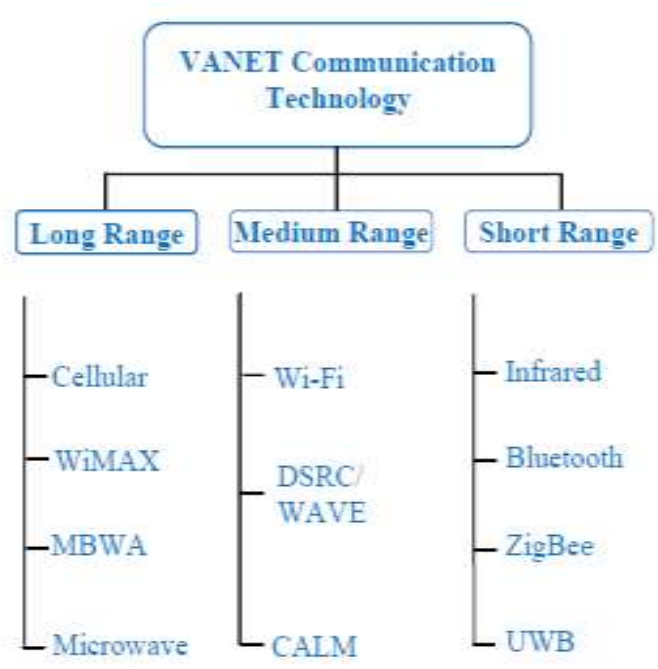

Fig.2. VANET Communication Technology Signal Range Wise

Figure 2 shows the VANET communication technology according to the signal range. So in that Worldwide Interoperability for Microwave Access (WiMAX) IEEE 802.16 is the key technology which is use for the long distance communication. WiMAX provides services like Internet access at the distance of up to $50 \mathrm{~km}$ with a speed of $70 \mathrm{Mbps}$. As it uses higher frequency band $(2.5 \mathrm{GHz})$ compared to Long Term Evaluation (LTE), it provides high bandwidth which in turn increases throughput. The new standard, WiMAX Mobile (IEEE 802.16m), uses advanced modulation techniques such as Adaptive modulation and coding (AMC), and Fast Channel Feedback to offer broadband access to mobile users. It can offer downlink data rates of up to $63 \mathrm{Mbps}$ and uplink data rates of $28 \mathrm{Mbps}$. A VANET application called 'Street Congestion Alert' is developed to assess the performances of $\mathrm{Wi}-\mathrm{Fi}$ and WiMAX technologies. The network performance model for these two networks inferences shows that the Mobile WiMAX performs better than WAVE (Wireless Access in Vehicular Environment) for larger network sizes [2].

The performance of VANET highly depends on its routing protocols [3]. Also we checked the results of our system by using AODV, AOMDV, DSDV and DSR routing protocols. The performance of two types of Ondemand routing protocols- Ad-hoc On-demand Distance Vector (AODV) routing protocol and Ad-hoc Ondemand Multipath Distance Vector (AOMDV) routing protocol. AOMDV incurs more routing overhead and packet delay than AODV but it had a better efficiency when it comes to number of packets dropped and packet delivery [4], [5].

Signals travelling through the channel experience different physical phenomena such as diffraction, scattering and reflection [6]. So the effect of above phenomena is very important in city area. Antenna plays an important role in wireless communication. Wireless capability is introduced with a Wi-Fi Antenna attached to an Antenna-mast also acting as the receiver station [7]. A new mobility model to derive the number of vehicles on the road and the probability of receiving the broadcasted packets successfully from all vehicles within the range of the transmitter. Probability of multi hop connectivity taking into account the location of relay vehicles and prove that MFR is not a valid scheme in VANETs [8].

\section{A. Multiple-Inputs-Multiple-Outputs (MIMO) -}

Single-Input-Single-Output systems represent a basic wireless communication link. Single-Input-MultipleOutput systems are configurations that provide receiveside diversity and provide additional robustness, but capacity improvement is not possible. Examples of SIMO systems are receivers with selection diversity schemes or Linear Maximal Ratio Combining (LMRC) schemes. Multiple-Input, Single-Output provides transmitter diversity in that it couples to the channel at a different point in space such that the links will not have the same fading characteristics though to the receive antenna and spatial sum of the signals will be dominated by the stronger of the two signals. Or in other way the transmitter signal design can be such that the combining at the single receiver can made in an optimal fashion as is done in Space-Time Coding Techniques. MIMO system de-multiplexes the source data stream into multiple independent channel streams and this provides for both advantages like redundancy and channel capacity improvement. The MIMO technique is also referred to as Spatial Division Multiplexing like a single source data stream is multiplexed between two spatial streams.

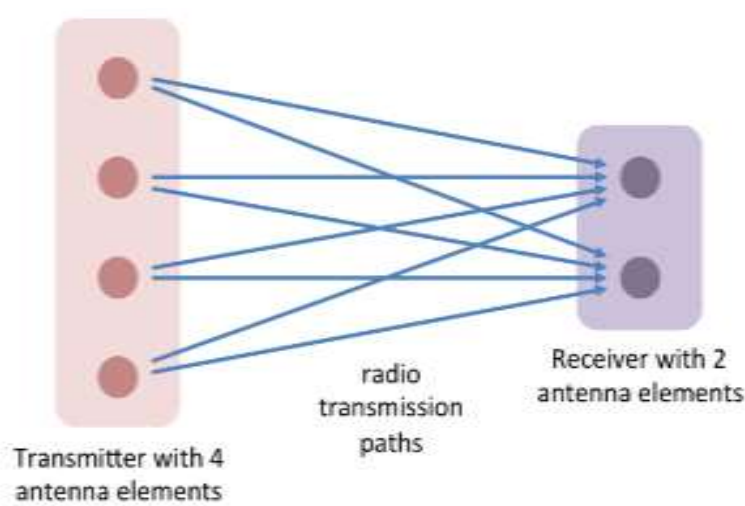

Fig.3. Example of 4 X 2 MIMO

In figure 3 , there are multiple radio transmission paths present in 4 X 2 MIMO system. The advantages of MIMO based wireless networks are increased distance range, throughput and also robustness of the data link. This advantage is achieved by mainly high throughput i.e ability to provide high data rate compared to range and then by using $40 \mathrm{MHz}$ channels to increase the available bandwidth for high data rate. Some other advantages of MIMO systems are better spectral efficiency at low cost, linear capacity growth i.e. 2 X 2 MIMO doubles the capacity and 4 X 4 MIMO quadruples capacity. 


\section{B. Adaptive Modulation and Coding (AMC) -}

In Adaptive Modulation and Coding scheme, first of all the system will check the value of Signal to Noise Ratio (SNR). If the SNR is low then system will select lower order modulation techniques like BPSK or QPSK and if the SNR is high then system will select higher order modulation techniques like 32 QAM or 64 QAM.

\section{METhodology}

The simulation parameters for designed system are given in table 1 . The vehicles which are present in the network have different speeds because in the actual world the speeds are not same for all the vehicles. In our work, we use four different routing protocols as given in table 1 .

Table 1. Simulation Parameters for Variable Speed Vehicles Environment Network

\begin{tabular}{|c|c|}
\hline Parameters & Quantity \\
\hline Frequency & $2.5 \mathrm{GHz}$ \\
\hline Bandwidth & $20 \mathrm{MHz}$ \\
\hline Speed (kmph) & $20,30,40,50,60,70,80$ \\
\hline Routing protocols & AODV, AOMDV, DSDV, DSR \\
\hline Type of antenna & Omni directional \\
\hline Packet size & 1000 Bytes \\
\hline Traffic type & UDP/CBR \\
\hline Mac & 802.16 \\
\hline Propagation model & Two ray ground radio propagation \\
model
\end{tabular}

The designing steps of the network are given below.

1) Set all the simulation parameters.

2) Create base station at the centre of the network.

3) Generate nodes with IP address, source and destination positions in the $\mathrm{X}-\mathrm{Y}$ plane.

4) Provide different speeds to the nodes.

5) Connect UDP and CBR to all transmitter nodes.

6) Connect NULL to all receiver nodes.

7) Connect transmitter and receiver nodes with each other.

Here we implement MIMO and AMC techniques in the WiMAX network. So while implementing MIMO technique, we connect 1 transmitter to 2-4 receivers and 2-4 transmitters to 1 receiver. In this way we generate multiple radio channels for transmission and reception of the data. In AMC technique, the modulation methods will change according to change in SNR value of the radio channel. The flow chart for whole designed system is given in figure 4 . The flow chart shows the brief information about flow of the designed VANET system.

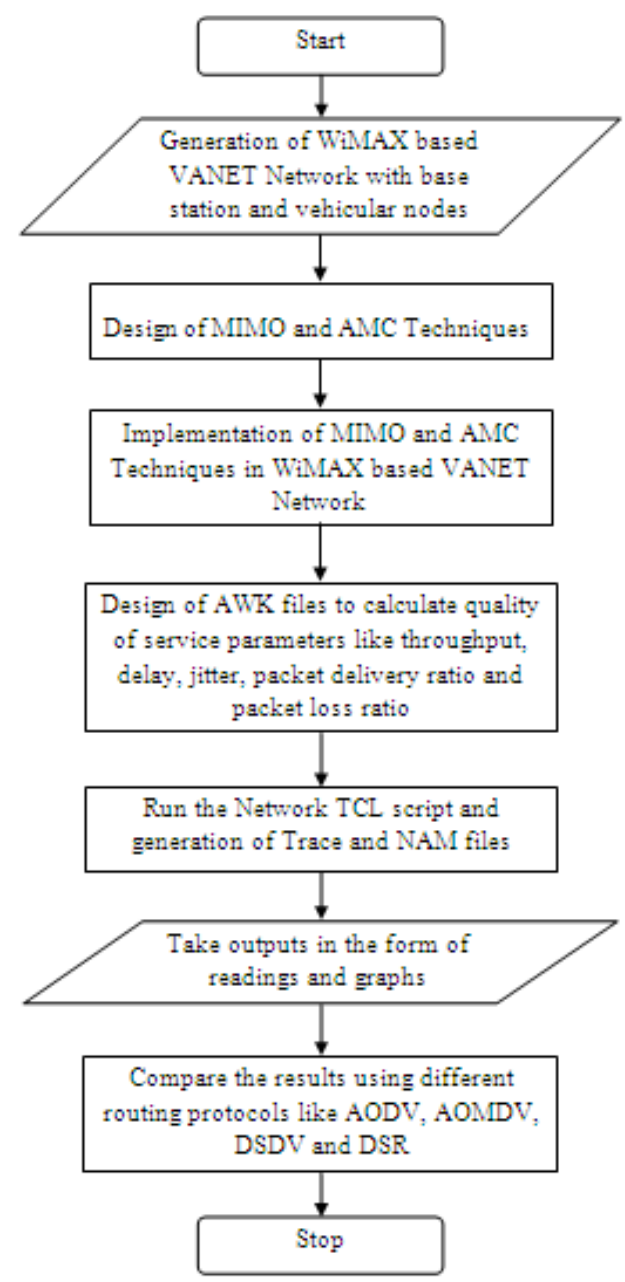

Fig.4. Flow Chart of the System

\section{RESULTS}

Following are the results for above said VANET system for AOMDV routing protocol on one channel i.e. data transmission and reception in between one transmitter and one receiver. All the results are taken by using designed system generated trace file. In figure 5 we can see that the vehicular nodes are transmitting and receiving the data through centralized base station. Data is shown by dotted lines.

Figure 6 and 7 shows that cumulative sum of sent and received bytes respectively for AOMDV routing protocol for one channel. Also figure 8 and 9 shows the throughput of sending and throughput of receiving bits respectively for AOMDV routing protocol. 


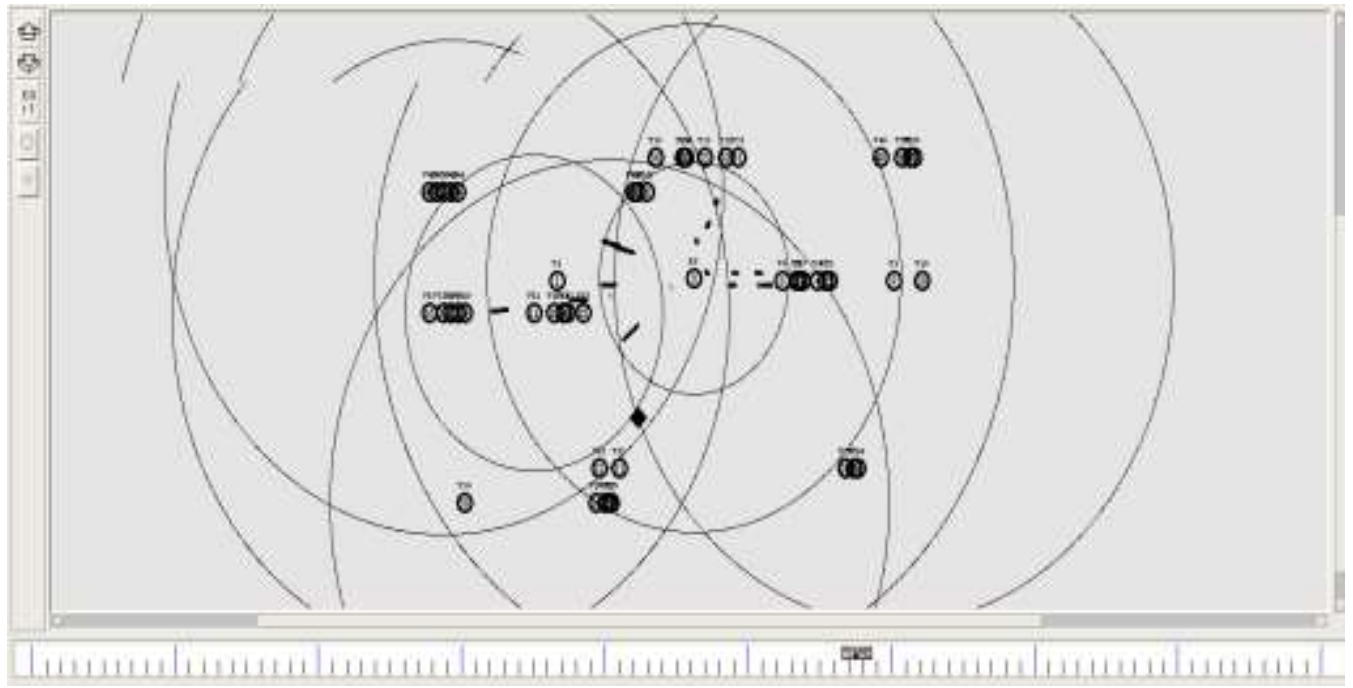

Fig.5. VANET Network on Network Animator for AOMDV Routing Protocol

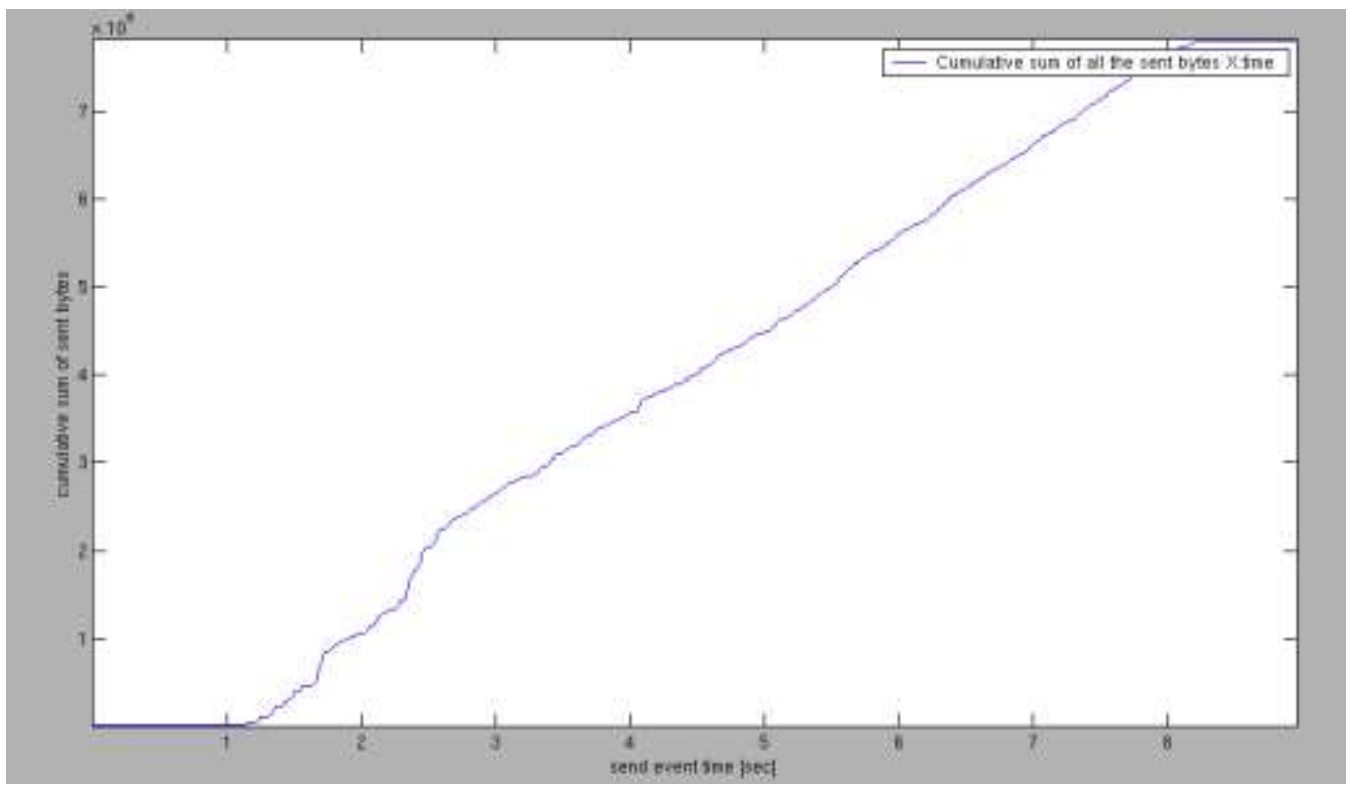

Fig.6. Cumulative Sum of Sent Bytes for AOMDV Routing Protocol

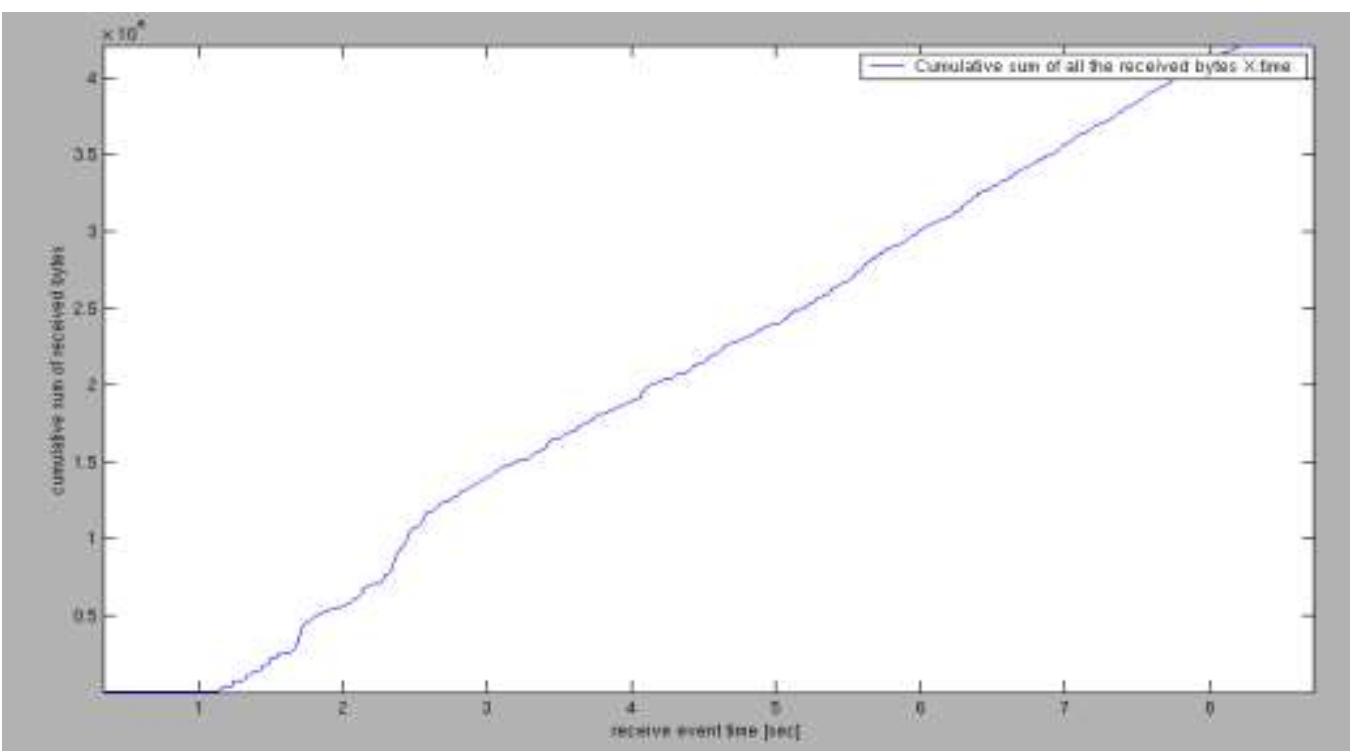

Fig.7. Cumulative Sum of Received Bytes for AOMDV Routing Protocol 


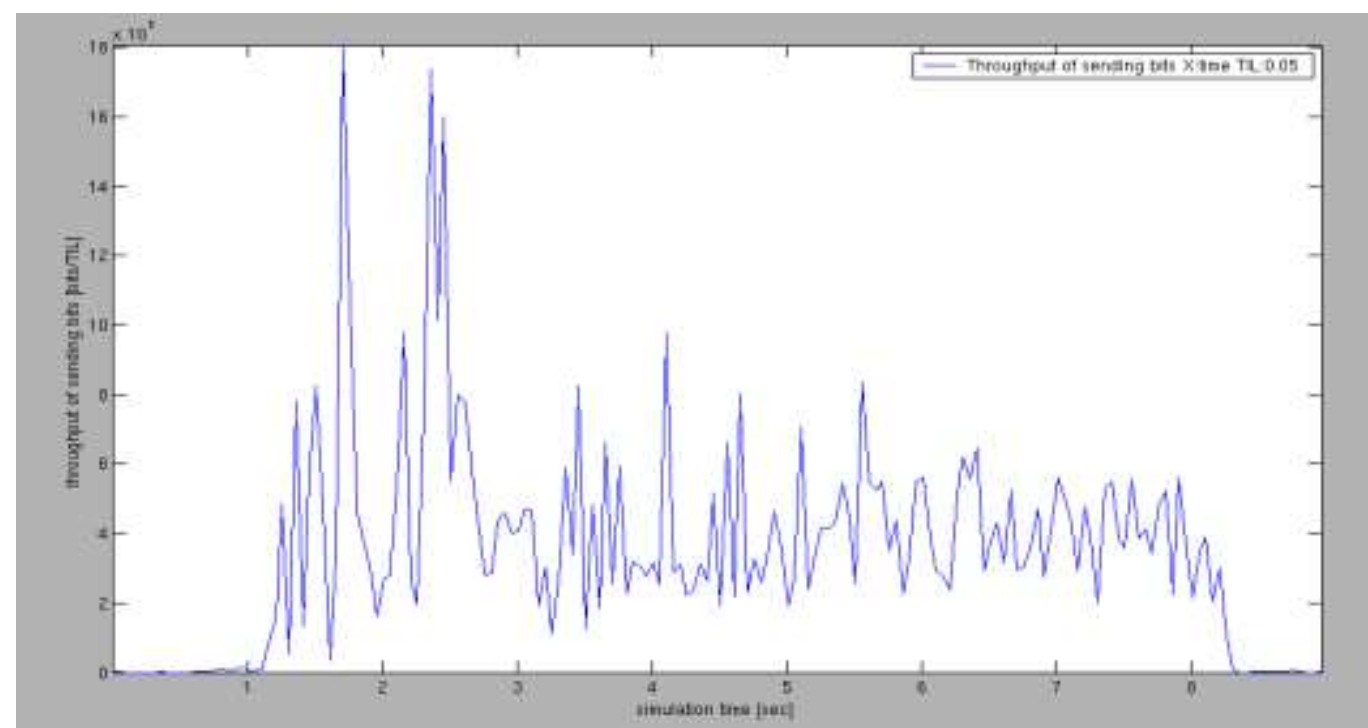

Fig.8. Throughput of Sending Bits for AOMDV Routing Protocol

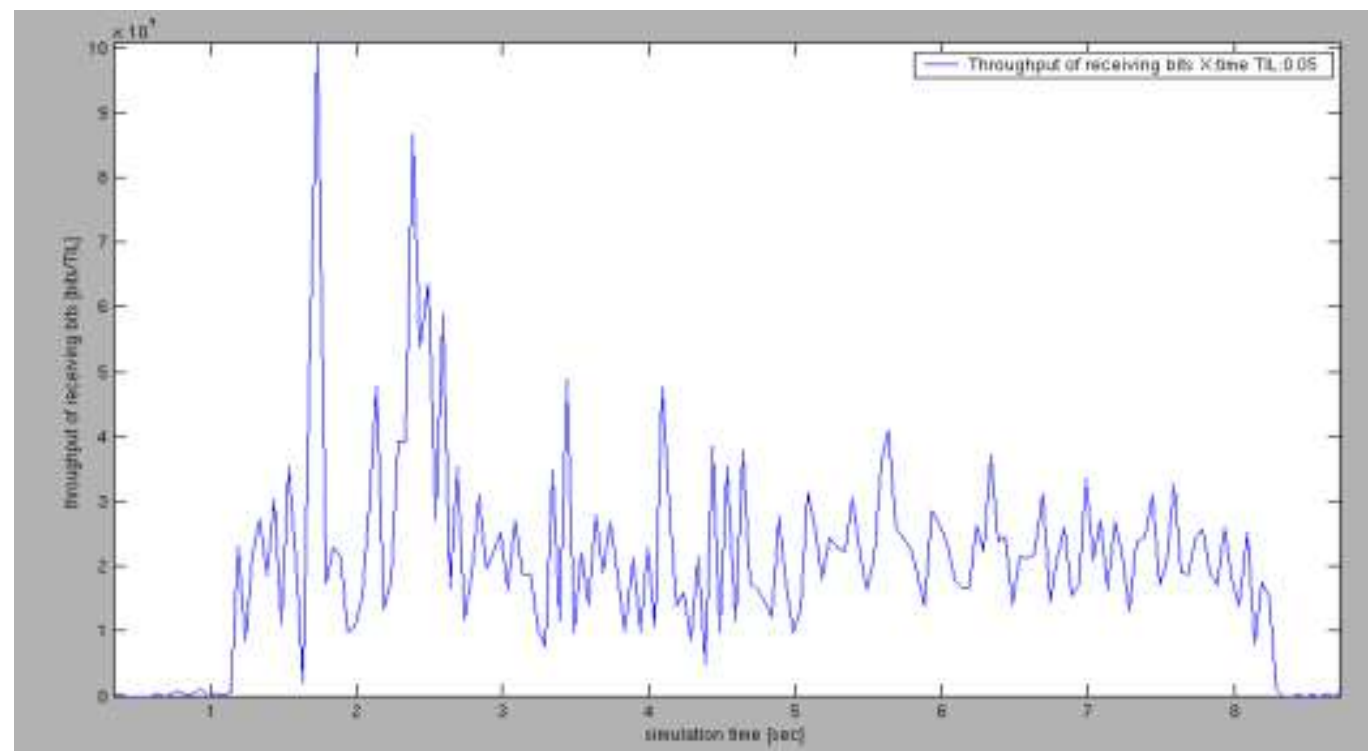

Fig.9. Throughput of Receiving Bits for AOMDV Routing Protocol

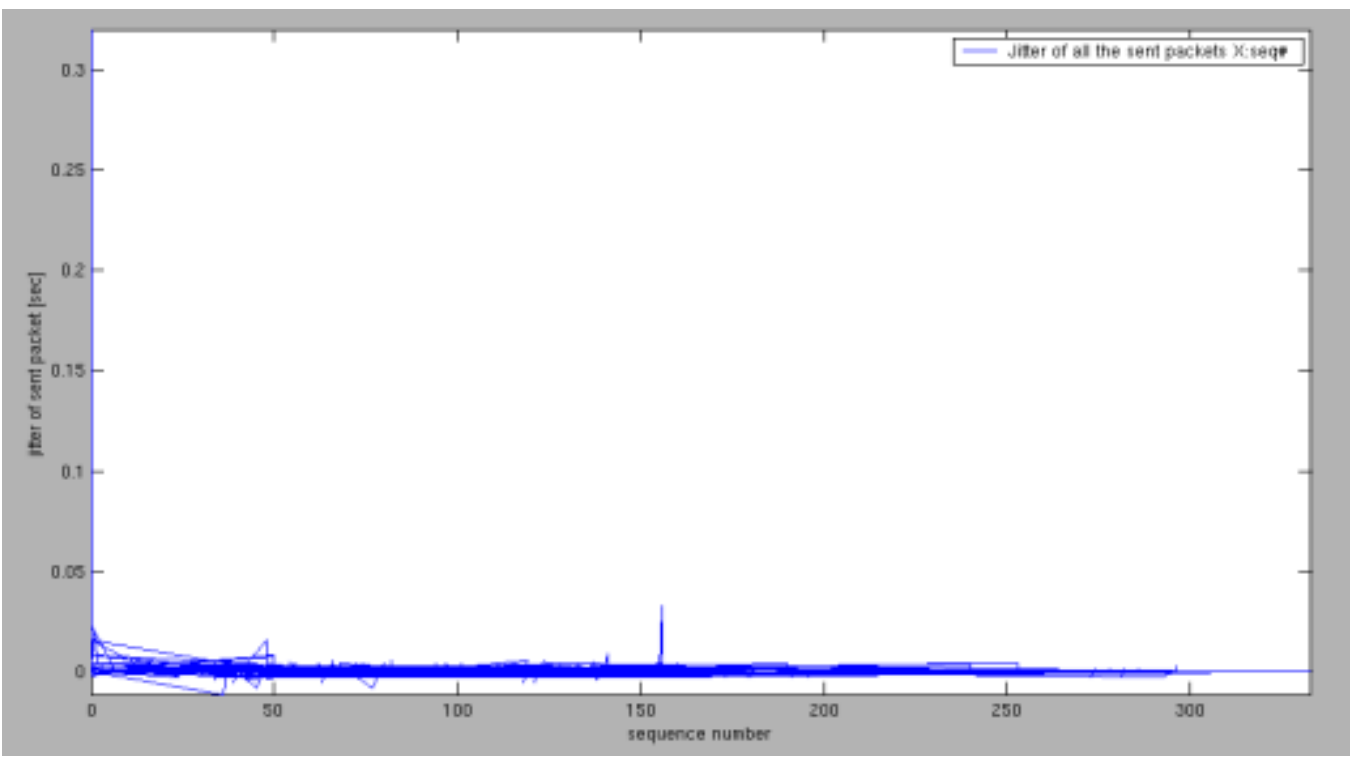

Fig.10. Jitter of Sent Packet for AOMDV Routing Protocol 


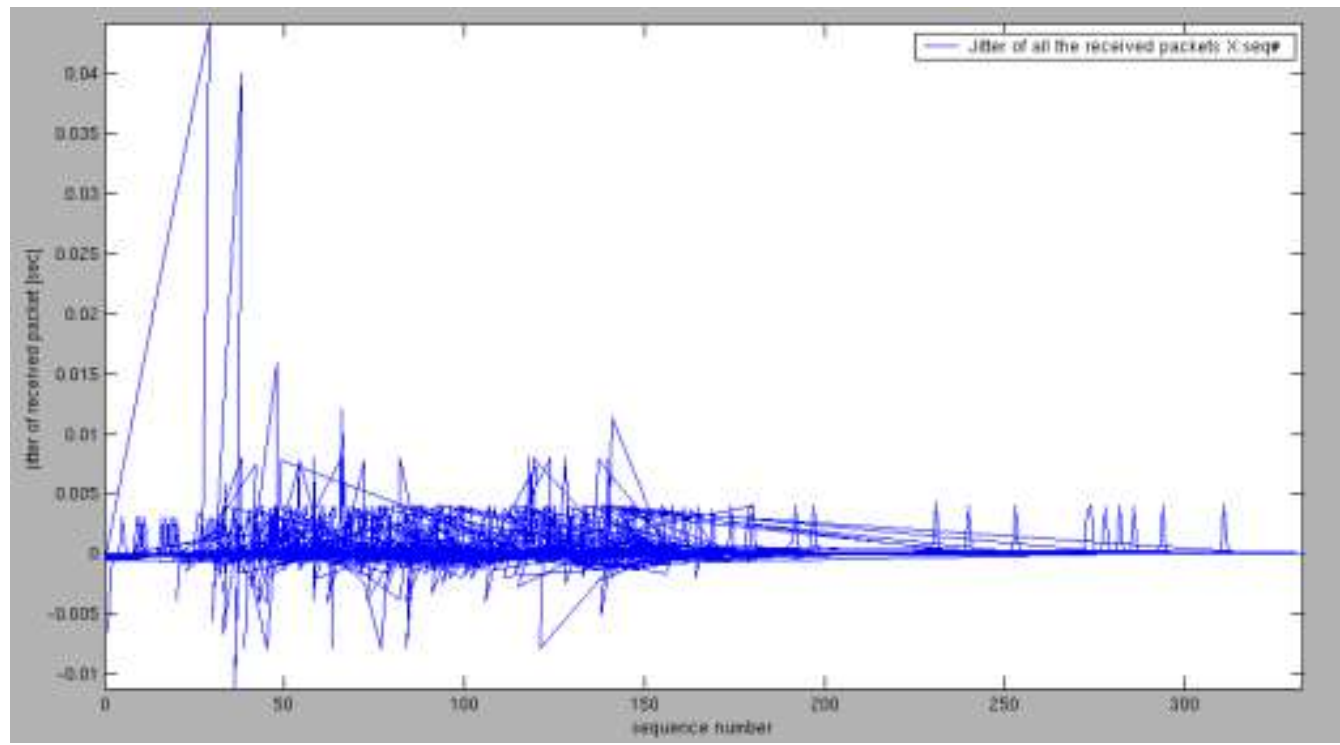

Fig.11. Jitter of Received Packet for AOMDV Routing Protocol

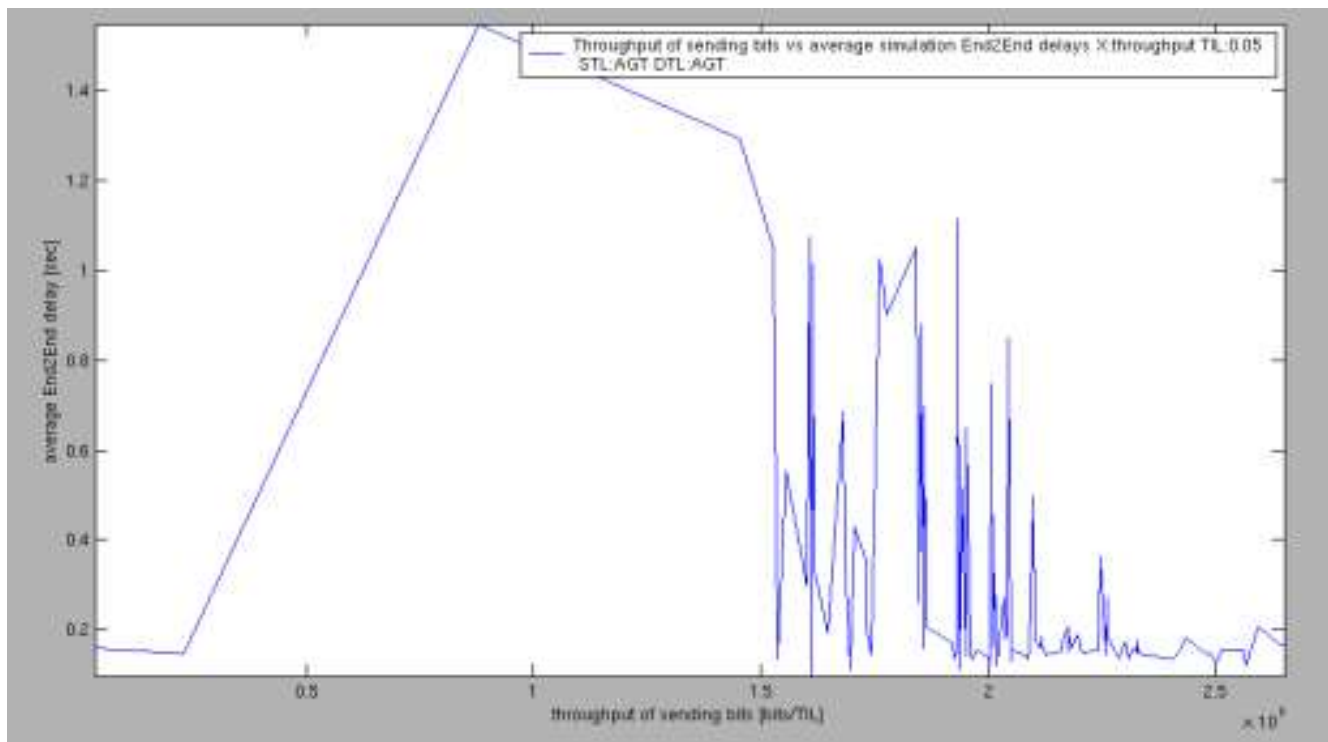

Fig.12. Throughput of Sending Bits Vs Average End2End Delay for AOMDV Routing Protocol

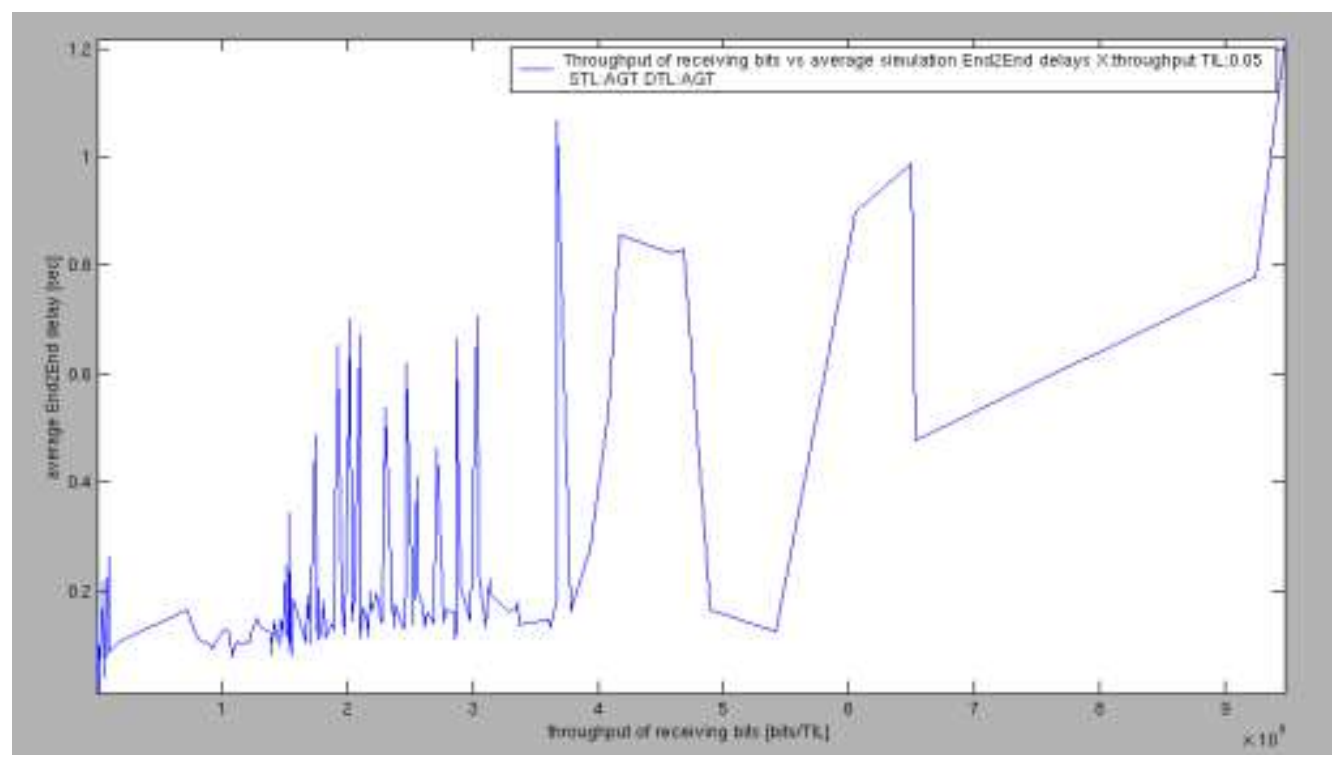

Fig.13. Throughput of Receiving Bits Vs Average End2End Delay for AOMDV Routing Protocol 


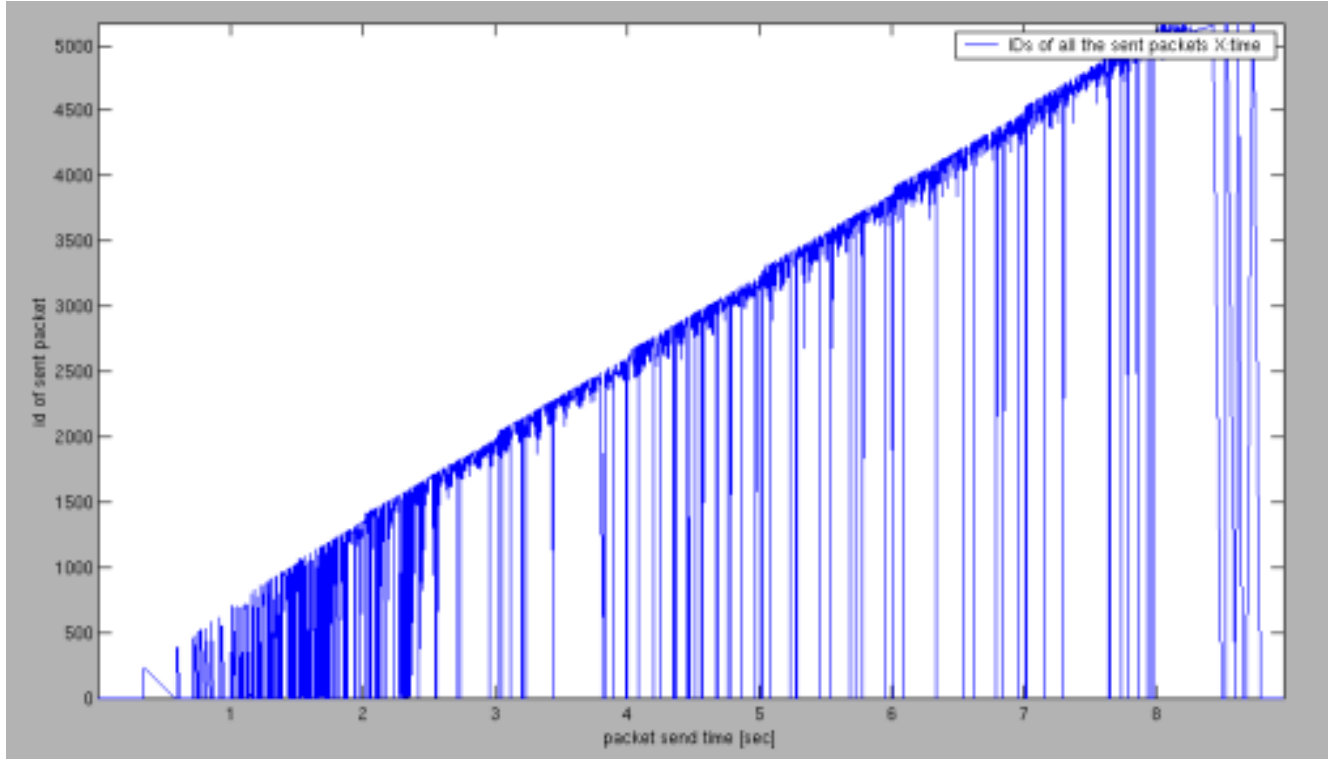

Fig.14. Packet Send Time Vs Id of Sent Packet for AOMDV Routing Protocol

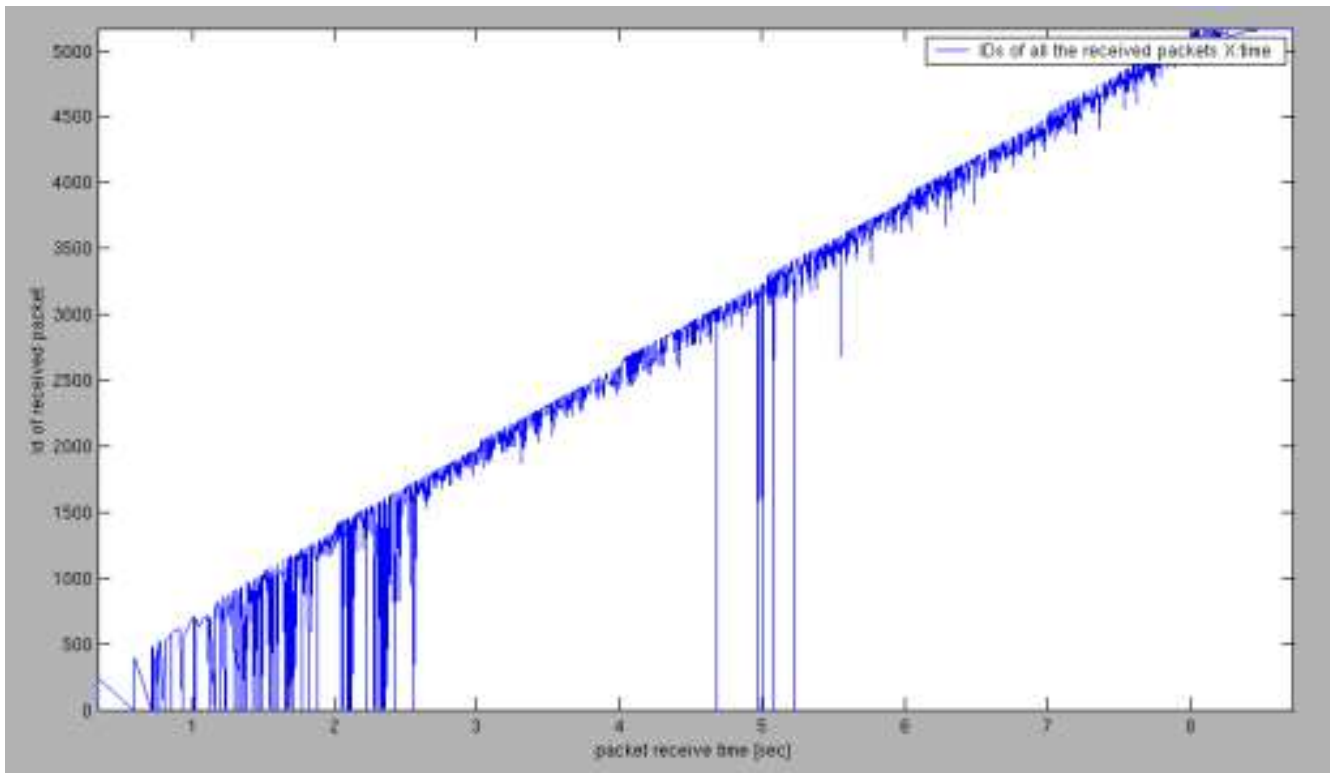

Fig.15. Packet Receive Time Vs Id of Received Packet for AOMDV Routing Protocol

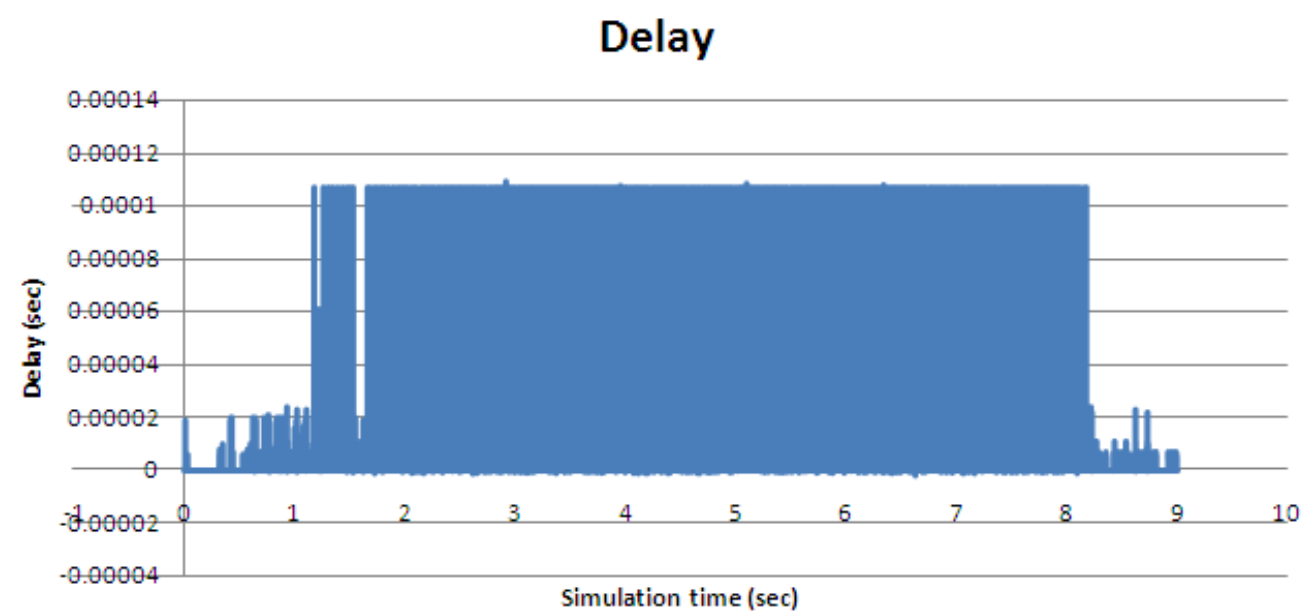

Fig.16. Simulation Time Vs Delay for AOMDV Routing Protocol 
Table 2. Overall Performance of the Designed VANET System

\begin{tabular}{|c|c|c|c|c|}
\hline QoS Parameters & AODV & AOMDV & DSDV & DSR \\
\hline Throughput (kbps) & 3654.22 & 4010.17 & 1781.17 & 2326.24 \\
\hline Maximum Delay (msec) & 0.11 & 0.11 & 0.11 & 0.11 \\
\hline Maximum Jitter (sec) & 0.25 & 0.04 & 0.04 & 0.04 \\
\hline Packet Delivery Ratio (\%) & 84.85 & 89.84 & 25.51 & 64.35 \\
\hline Packet Loss Ratio (\%) & 15.15 & 10.16 & 74.49 & 35.64 \\
\hline
\end{tabular}

Table 2 shows the overall performance of the designed VANET system for AODV, AOMDV, DSDV and DSR routing protocols.

Above graphs and table 2 shows the comparison of results of our designed system with different routing protocols, in which AOMDV routing protocol provides better outputs with respect to throughput, maximum delay, maximum jitter, packet delivery ratio and packet loss ratio. Because of these better outputs for AOMDV routing protocol, the VANET system can work better with AOMDV routing protocol in terms of above said quality of service parameters.

\section{CONCLUSION}

The WiMAX based variable speed vehicles environment VANET system works faster than the existing systems. The designed VANET system shows that the overall performance of the AOMDV routing protocol is better than other three routing protocols in terms of quality of service parameters as shown in table 2 . The DSDV routing protocol provides lower outcome in terms of throughput, maximum delay, maximum jitter, packet delivery ratio and packet loss ratio than other routing protocols. The reason behind is that DSDV is the proactive routing protocol. This type of protocols maintains fresh lists of destinations and their routes by periodically distributing routing tables throughout the network. The main disadvantages of such protocols are, it requires respective amount of data for maintenance and slow reaction on restructuring and failures.

\section{FUTURE SCOPE}

In future the different types of routing protocols can be use to improve the quality of service parameters. Different types of data can be used for transmission and reception in WiMAX based VANET system. Also the use of different encryption and decryption algorithms can improve the overall performance of the VANET system.

\section{REFERENCES}

[1] Ho-Yeon Kim, Dong-Min Kang, Jun-Ho Lee and TaiMyoung Chung, "A Performance Evaluation of Cellular Network Suitability for VANET", World Academy of Science, Engineering and Technology, International Scholarly and Scientific Research \& Innovation, Volume 6, April 2012.

[2] R. Bhakthavathsalam, and Starakjeet Nayak, "Operational
Inferences on VANETs in 802.16e and 802.11p with Improved Performance by Congestion Alert," the 8th Annual IEEE Consumer Communications and Networking Conference, 2011.

[3] Prabhakar D. Dorge, Sanjay S. Dorle, Megha B. Chakole, Dhiraj K. Thote, "Improvement of QoS in VANET with Different Mobility Patterns", IEEE International Conference on Radar, Communication and Computing (ICRCC), SKP Engineering College, Tiruvannamalai, TN., India. pp.206-209, IEEE, ISBN 978-1-4673-2756-5, 21 - 22 December, 2012.

[4] B. Sreedevi, Y. Venkatramani, and T. R. Sivaramakrishnan, "Performance Comparison using AODV and AOMDV Protocols in Heterogeneous Hybrid Cluster Routing using Partial Authority Nodes in Mobile Ad hoc Networks," European Journal of Scientific Research, ISSN 1450-216X Vol.58 No.4 (2011), pp.542549, EuroJournals Publishing, Inc. 2011.

[5] S. R. Biradar, Koushik Majumder, Subir Kumar Sarkar, and Puttamadappa C, "Performance Evaluation and Comparison of AODV and AOMDV," S.R.Biradar et al. / (IJCSE) International Journal on Computer Science and Engineering Vol. 02, No. 02, 373-377, 2010.

[6] Divya Choudhary and Aaron L. Robinson, "A New Approach to Wireless Channel Modeling using Finite Mixture Models", International Journal of Digital Information and Wireless Communications (IJDIWC) 4(2): 169-183, The Society of Digital Information and Wireless Communications, (ISSN: 2225-658X), 2014.

[7] Imran Jattala, Junaid Farooqi, Shakeel Durrani and Nassar Ikram, "Wireless Sensor Network (WSN) based Automatic Firing Practice System (AFPS) for Training of Law Enforcement Agencies (LEAs)", International Journal of Digital Information and Wireless Communications (IJDIWC) 4(4): 408-417 The Society of Digital Information and Wireless Communications, (ISSN: 2225-658X), 2014.

[8] Khalid Abdel Hafeez, Lian Zhao, Zaiyi Liao, and Bobby Ngok-Wah Ma, "Impact of Mobility on VANETs' Safety Applications," IEEE Globecom, 2010.

\section{Authors' Profiles}

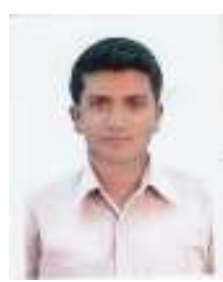

Prabhakar D. Dorge is pursuing his Ph.D. from R.T.M. Nagpur University, Nagpur, India. He received his M.Tech degree in Microwave Communication from College of Engineering Pune, India in 2011. He has worked as reviewer for International \& National conference. He is a member of ISTE, IACSIT, IAENG and UACEE. His research activities focus on protocols for wireless and computer networks, wireless communication. 


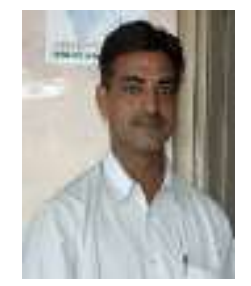

Dr. Sanjay S. Dorle received his B.E. degree from YCCE Nagpur and M.Tech. (Electronics Design \& Technology) degree from CEDTI, Gorakhpur, India in 1997 and 2002, respectively. He has completed Ph.D. from VNIT Nagpur. He has worked as reviewer for many International \& National conferences. He is a member of IEEE, CSI, and ISTE. His research areas include VANET, Embedded Electronics Systems, etc. He is also recipient of Best Teacher Award for 2008-09.

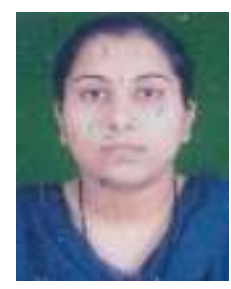

Megha B. Chakole received her B.E. degree \& M.Tech. (Electronics) degree from R. T. M. Nagpur University, India in 2003 and 2008 respectively. She is pursuing Ph.D. from R. T. M. Nagpur University.

She has published many research papers in International conferences and journals. She has worked as reviewer for International \& National conferences. She is a member of ISTE. Her research areas include Wireless Communications, Embedded Electronics Systems, etc. She is currently working as Assistant Professor with YCCE in Electronics \& Telecommunication Engineering Department, Nagpur, India.

How to cite this paper: Prabhakar D. Dorge, Sanjay S. Dorle, Megha B. Chakole,"Implementation of MIMO and AMC Techniques in WiMAX Network based VANET System", International Journal of Information Technology and Computer Science(IJITCS), Vol.8, No.2, pp.60-68, 2016. DOI: 10.5815/ijitcs.2016.02.08 